Ortodonti ile ilgili

YouTubeTM video

platformunda yer alan

Türkçe dilindeki

videoların bilgi

sağlama kalitesinin

değerlendirilmesi

\section{Evaluation of information providing quality of Turkish-language videos on YouTubeTM video platform related to orthodontics}

\author{
Dr. Öğr. Üyesi Gökhan Türker \\ Erciyes Üniversitesi, Diş Hekimliği Fakültesi, \\ Ortodonti A.D., Kayseri
}

Orcid ID: 0000-0001-5295-2722

\author{
Öğr. Gör. Taner Öztürk \\ Erciyes Üniversitesi, Diş Hekimliği Fakültesi, \\ Ortodonti A.D., Kayseri
}

Orcid ID: 0000-0003-1670-286X

Geliş tarihi: 12 Ocak 2021

Kabul tarihi: 29 Haziran 2021

doi: 10.5505/yeditepe.2022.20082

\section{Yazışma adresi:}

Öğr. Gör. Taner Öztürk

Erciyes Üniversitesi, Diş Hekimliği Fakültesi,

Ortodonti A.D. Köşk Mah. Ahmet El-Biruni Cad. No:52 38039 Kayseri

Tel: +90 2076666 (Dahili: 29100)

E-posta: tanertr35@gmail.com
ÖZET

Amaç: Bu çalışmanın amacı ortodonti ile ilgili YouTube ${ }^{\mathrm{TM}}$ video platformunda yer alan Türkçe dilindeki videolarda sunulan bilgilerin güvenilirliğinin ve doğruluğunun değerlendirilmesidir.

Gereç ve Yöntem: YouTube ${ }^{\mathrm{TM}}$ video platformunda yer alan "Ortodonti" terimini içeren videolar aratılmıştır. Video aramasında en çok izlenen Türkçe dilindeki videolar belirlenmiş ve bu videoların bilgi sağlama kalitesi değerlendirilmiştir. Toplamda 60 video izlenmiş ve dahil edilmeme kriterleri göz önünde bulundurularak 36 video çalışmaya dahil edilmiştir. Videolara ait görüntülenme sayıları, süreleri, yüklenme tarihinden geçen zamanları, beğenilme, beğenilmeme ve yorum sayıları belirlenmiştir. İstatistiksel değerlendirmede Shapiro-Wilks normalite, Mann-Whitney U, Kruskall Wallis, Pearson $\mathrm{Ki}$-Kare ve Fisher's Exact testleri kullanılmıştır.

Bulgular: Videoların bilgi sağlama kalitesi değerlendirilmiş ve 23 videonun yetersiz, 13 videonun orta/iyi kalitede olduğu belirlenmiştir. Yetersiz ve orta/iyi kalitedeki videolar arasında video süresinde, yükleme tarihinden geçen zamanda ve etkileşim indeksinde istatistiksel olarak anlamlı farklılıklar olduğu görülmüştür $(p<0,05)$. Video yükleme kaynağına göre 11 videonun bireysel, 9 videonun doktor ve 15 videonun ise ticari kaynaklı olduğu belirlenmiş ve görüntülenme, beğenilme ve beğenilmeme sayılarında, izlenme oranlarında istatistiksel olarak anlamlı farklılıklar olduğu tespit edilmiştir $(p<0,05)$.

Sonuç: YouTube ${ }^{\mathrm{TM}}$ video platformunda bulunan ortodonti ile ilgili Türkçe dilindeki videoların bilgi sağlama kalitesi genel olarak yetersizdir. YouTube ${ }^{\mathrm{TM}}$ gibi internet platformlarında yer alan bilgilerin yetersizliği konusunda hastalar ve sağlık profesyonelleri bilgi sahibi olmalıdır.

Anahtar kelimeler: Ortodonti, YouTube, İnternet araştırmaları SUMMARY

Aim: The aim of this study is to evaluate the reliability and accuracy of the informations in Turkish language presented on the YouTube ${ }^{\mathrm{TM}}$ video platform about orthodontics.

Materials and Methods: Videos containing the term "Orthodontics" was searched on the YouTube ${ }^{\mathrm{TM}}$ video platform. The most watched Turkish language videos in the video search were determined and the quality of information provision of these videos was evaluated. A total of 60 videos were watched and 36 videos were included in the study, considering the exclusion criteria. The number of views, duration, time passed from the upload date and the number of likes, dislikes and comments of the videos were determined. Shapiro-Wilks normality, Mann-Whitney U, Kruskall Wallis, Pearson Chi-Square and Fisher's Exact tests were used for statistical evaluation.

Results: The quality of information provision of the videos was evaluated and it was determined that 23 videos were insufficient and 13 videos were medium/good quality. It was observed that there were statistically significant differences between insufficient and medium/good quality videos in vi- 
deo duration, time after upload date and interaction index ( $p<0.05$ ). According to the video upload source, it was determined that 11 videos were individual, 9 videos were doctors and 15 videos were commercial, and statistically significant differences were found in the number of views, likes and dislikes and viewing rates $(p<0.05)$.

Conclusion: The quality of information provided by the videos about orthodontics in Turkish language on the YouTube $^{\mathrm{TM}}$ video platform is generally insufficient. Patients and healthcare professionals should be aware of the insufficiency of information on internet platforms such as YouTube ${ }^{\mathrm{TM}}$.

Key words: Orthodontics, YouTube, internet research GiRiş

Ortodontik tedavilerde en önemli amaçlardan biri, sağlık alanlarının tümünde olduğu gibi, hastalara bilgileri etkili bir şekilde iletmektir. ' Son zamanlarda, estetik beklentilerin artmasına bağlı olarak her yaş grubundan ve sosyoekonomik düzeyden bireylerin ortodontik tedavi istekleri de artmaktadır. ${ }^{2}$ Ortodontik tedavi gören ve ortodontik tedavi görme potansiyeline sahip hastaların ortodontik tedaviler ile ilgili tüm riskler konusunda tam olarak bilgilendirilmesi gereklidir. ${ }^{3}$ Sağlık çalışanları ve sağlık kuruluşları hastalara sağ ıkla ilgili bilgiler sağlamalarına rağmen internete erişilebilirliğin artması, hastaların daha fazla bilgilendirilme istekleri ve profesyonel sağlık hizmetlerine kıyasla daha düşük maliyetler nedeniyle, tıbbi bilgi aramak için internetin kullanımında son yıllarda önemli bir artış olmuştur. $^{4}$

İnternete erişimin kolaylığı ve internet üzerinde çok çeşitli bilgi kaynaklarının mevcut olması, internetin insan hayatının vazgeçilmez bir parçası ve temel bilgi kaynağı haline gelmesine neden olmuştur. Tıp ve diş hekimliği alanında bilgi edinmek isteyen insanlar hekimlerden önce internete başvurmakta ve profesyonel bir teşhis aramadan önce sağlık durumları üzerine araştırma yapmaktadırlar. ${ }^{5}$ Hastalar genellikle sağlık bilgilerini ararken görsel ve işitsel bilgiler sağlayan YouTube ${ }^{\mathrm{TM}}$ video paylaşım platformunu kullanmayı tercih etmektedir., ${ }^{1,2}$ YouTube ${ }^{\mathrm{Tm}}$ 'a bilgisayarlar, akıllı telefonlar ve televizyonlar üzerinden erişilebilmesi nedeniyle video paylaşım platformu YouTube ${ }^{\text {Tm }}$ bir milyardan fazla kullanıcısı ile dünyanın en popüler ikinci web sitesidir. ${ }^{5,6}$ YouTube $^{\mathrm{TM}}$ videoları hem eğitici hem de eğlenceye yönelik içeriklere sahip olabilirler; ancak, bilimsel bir hakem değerlendirme sürecine veya kabul için standartlaştırılmış bir metodolojiye sahip olmamaları nedeniyle

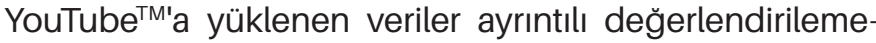
mekte ve yanlış bilgilerin yayılmasına neden olabilmektedir. ${ }^{7}$ Literatürde ortodontik tedaviler, dudak-damak yarıkları, üst çene genişletmesi, lingual ortodonti, ortodontik retansiyon, hareketli ortodontik apareyler, ortognatik cerrahi gibi Ortodonti alanı ile ilgili YouTube videolarının içeriğini analiz eden çeşitli araştırmalar mevcuttur. ${ }^{2,35-10}$ Kılınç ve Sayar, ortodonti konusunda YouTubeTM videolarının güvenilirliğinin değerlendirdikleri çalışmalarında İngilizce dilindeki videoları değerlendirmişler ve videoların güvenilirliğinin düşük dereceli olduğunu, ortodontistlerin You$T^{T} \mathrm{bue}^{\mathrm{T} \mathrm{M}}$ 'da hastalara yol gösteren yetersiz verilere dikkat etmeleri gerektiğini belirtmişlerdir.?

Bu çalışmanın amacı ortodonti ile ilgili Türkçe dilindeki YouTube $^{\mathrm{TM}}$ videolarının hastalar için güvenilirliğinin analiz ederek, bu videoların sağladığı bilgilerin kalitesini ve doğruluğunu değerlendirmektir.

\section{GEREÇ VE YÖNTEM}

Bu çalışmada halka açık olan bir internet video platformu (YouTube ${ }^{\mathrm{TM}}$ ) kullanıldığından ve herhangi bir bireye ait veri kullanılmadığından dolayı etik kurul onayı alınmamıştır.

Bu çalışmanın başlangıcında en uygun terimin seçilebilmesi için ortodontik tedavi ile ilgili bilgi arayışında olan hastaların sıklıkla kullandığı üç terim (Ortodontik tedavi, ortodonti, tel tedavisi) Google Trends (Google Trends, 2020, Alphabet, ABD) internet yazılımı kullanılarak değerlendirilmiştir. Bu işlem sonrasında bireylerin Youtube video platformunda en sık kullandığı terimin "Ortodonti" olduğu belirlenmiş ve arama için bu terim seçilmiştir (Re$\operatorname{sim} 1)$.

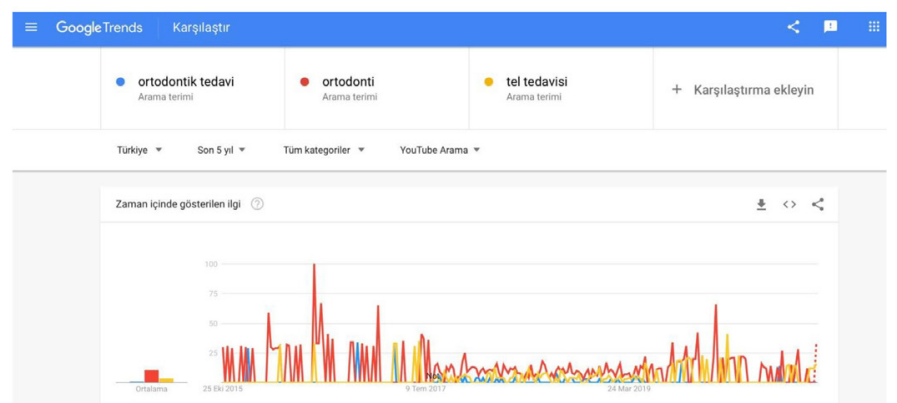

Resim 1. Anahtar kelimenin belirlenmesinde kullanılan Google Trends sayfas görüntüsü.

YouTube $^{\mathrm{TM}}$ internet sitesi (https://www.youtube.com) kullanılarak izlenen videolar aynı gün (1 Kasım 2020) ve tek bir araştırmacı tarafından değerlendirilmiştir. Video araması sırasında sadece görüntüleme sayısına göre bir sıralama olması sağlanmış ve en çok izlenen videoların bilgi sağlama kalitesi değerlendirilmiştir. Sadece Türkçe dilindeki videolar incelenmiştir.

Çalışmanın dahil etmeme kriterleri; anlatım dilinin Türkçe olmaması, konu ile ilgisiz olması, reklam olması, konferans veya ders videosu olması ve tekrar olması olarak belirlenmiştir. Desai ve arkadaşlarının çalışmasında bireylerin büyük çoğunluğunun YouTubeTM'da yer alan medikal videoların ilk 60 tanesini izlemeye odaklandıklarını bildirmiştir. ${ }^{11}$ Bu nedenle YouTube ${ }^{\mathrm{TM}}$ üzerinden video incelemesi sırasında ilk 60 video izlenmiş ve hariç tutma kriterleri (anlatım dilinin Türkçe olmaması ' $n=6$ ', konu ile ilgisiz olması ' $n=4$ ', reklam içeriği olması ' $n=3$ ', tekrarlayan video olması ' $n=8$ ', konferans/ders içeriği olması ' $n=3^{\prime}$ )'de uygulandığında toplam 36 video çalışmaya dahil edilmiştir. 
Çalışmaya dahil edilen videolara ait;

1.Görüntülenme sayısı,

2.Video süresi (dakika),

3.Yüklenme tarihinden geçen zaman (gün),

4.Beğenilme sayısı,

5.Beğenilmeme sayısı,

6.Yorum sayısı,

7.Etkileşim indeksi (\%) ve

8. İzlenme oranı (\%) parametreleri kullanılmıştır.

Etkileşim indeksinin ve izlenme oranının hesaplanması için kullanılan formüller Resim 2 'te gösterilmiştir.

$$
\begin{aligned}
& \text { Etkileşim indeksi }=\left[\frac{\text { Beğenilme Sayısı }- \text { Beğenilmeme Sayısı }}{\text { İzlenme Sayısı }} x 100\right] \\
& \text { İzlenme oran }=\frac{\dot{\text { İlenme sayıs }}}{\text { Yüklenme tarihinden beri geçen } \text { zaman }} \times 100
\end{aligned}
$$

Resim 2. Etkileşim indeksi ve İzlenme oranı formülasyonları.

Videoların kalite kategorisinin belirlenmesinde her video için 8 başlık (1- Tanımlama, 2- Endikasyon, 3- Kontrendikasyon, 4- Avantaj, 5- Prosedür, 6- Komplikasyon, 7- Prognoz ve kalıcılık, 8- Maliyet) ile ilgili bilgi sağlama değerlendirmesi yapılmıştır. ${ }^{9}$ Her başlık için olması durumunda 1 skoru, olmaması durumunda 0 skoru kullanılmıştır. Değerlendirme sonunda her videonun toplam puana göre bilgi sağlama kalite kategorisi yetersiz (0-3 puan), orta/iyi (4-8 puan) şeklinde iki başlık altında incelenmiştir. Ayrıca her videoya ait video yükleme kaynağı (bireysel, doktor, ticari) ve videonun yüklenme amacı (hasta deneyimi, hasta bilgilendirilmesi, genel bilgi sağlanması) kaydedilmiştir.

\section{İstatistiksel Analiz}

Her videoya ait parametreler Microsoft Excel bilgisayar yazılımı kullanılarak kaydedilmiştir. Elde edilen verilerin istatistiksel analizi Statistical Package of Social Sciences (SPSS, Ver. 26.0, IBM, Armonk, USA) bilgisayar programı kullanılarak gerçekleştirilmiştir. Verilerin normal dağılıp dağılmadığının belirlenmesinde Shapiro-Wilks normalite testi kullanılmıştır. Non-parametrik verilerin değerlendirilmesinde ikili karşılaştırmalar için Mann Whitney-U testi, üçlü karşılaştırmalar için Kruskall Wallis testi kullanılmıştır. Verilerin korelasyonunun değerlendirilmesinde Spearman Korelasyon Katsayısı kullanılmıştır. Kategorik verilerin değerlendirilmesinde Pearson Ki-Kare ve Fisher's Exact testleri kullanılmıştır. İstatistiksel anlamlılık değeri $p<0,05$ olarak belirlenmiştir.

\section{Güvenilirlik Analizi}

Araştırmacı içi güvenilirliğin değerlendirilmesi amacıyla çalışmaya dahil edilen videolardan rastgele seçilen 8 tanesi aynı araştırmacı tarafından ilk izlemden 3 ay sonra yeniden izlenerek videoların kalite puanı açısından yeniden değerlendirme yapılmıştır. İki izlem arasındaki ilişkinin değerlendirilmesi için sınıf içi korelasyon katsayısı (ICC) kullanılmış ve 0,876-0,935 arasında kabul edilebilir bir güvenirlik ve tekrarlanabilirlik olduğu belirlenmiştir. Ayrıca iki ölçüm arasında Wilcoxon Rank testi ile analiz yapıldığında anlamlı farklıık olmadığı bulunmuştur $(\mathrm{p}<0.05)$.

\section{BULGULAR}

Çalışmada, dahil edilmeme kriterlerine göre değerlendirme yapılarak "Ortodonti" teriminin kullanıldığı ilk 60 video analiz edilmiş ve belirlenmiş olan kriterlere göre 36 video çalışmaya dahil edilerek 24 video çalışma dışı bırakılmışıı. Dahil edilen videoların tanımlayıcı istatistiksel değerlendirme sonuçlarına göre izlenme sayısının $94377,11 \pm 123883,01$, beğenilme sayısının $318,44 \pm 616,93$ beğenilmeme sayısının $29,53 \pm 48,40$, etkileşim indeksinin $0,33 \pm 0,58$ ve izlenme oranının $13400,50 \pm 42940,23$ olduğu bulunmuştur (Tablo 1).

Tablo 1. Videoların tanımlayıcı istatistiksel değerlendirme sonuçları.

\begin{tabular}{|l|l|l|}
\hline & Ort. \pm S.S. & Median (Min / Max) \\
\hline Görüntülenme sayısı (n) & $94377,11 \pm 123883,01$ & $58555,50(25010,00 / 692586,00)$ \\
\hline Video süresi (dakika) & $4,25 \pm 6,68$ & $1,48,(0,23 / 31,00)$ \\
\hline Yüklenme tarihinden beri geçen zaman (gün) & $1808,64 \pm 799,59$ & $1515,00(38,00 / 3403,00)$ \\
\hline Beğenilme sayısı (n) & $318,44 \pm 616,93$ & $147,501(3,00 / 3600,00)$ \\
\hline Beğenilmeme sayısı (n) & $29,53 \pm 48,40$ & $15,00(0,00 / 242,00)$ \\
\hline Yorum Sayısı (n) & $68,00 \pm 112,88$ & $14,00(0,00 / 387,00)$ \\
\hline Etkileşim İndeksi (\%) & $0,33 \pm 0,58$ & $0,16(-0,01 / 3,45)$ \\
\hline İlenme Oranı (\%) & $13400,50 \pm 42940,23$ & $3425,69(1042,11 / 256255,26)$ \\
\hline Ort.: Ortalama, S.S.: Standart Sapma, Min: Minimum, Max: Maksimum.
\end{tabular}

Videoların bilgi sağlama değerlendirmesi sonucunda 23 videonun yetersiz (0-3 puan), 13 videonun orta/iyi (4-8 puan) kalitede olduğu belirlenmiştir. Bilgi içeriği seviyesine göre gruplar arasında video süresinde, yükleme tarihinden geçen zamanda ve etkileşim indeksinde istatistiksel olarak anlamlı farklılıklar olduğu görülmüştür (Tablo 2).

\begin{tabular}{|c|c|c|c|c|c|}
\hline & \multicolumn{2}{|c|}{$\begin{array}{l}\text { Yetersiz Kaliteli Videolar } \\
\qquad(\mathbf{n}=23)\end{array}$} & \multicolumn{2}{|c|}{ Orta/Iyi Kaliteli Videolar $(\mathrm{n}=\mathbf{1 3})$} & \multirow[t]{2}{*}{$\begin{array}{l}\mathbf{P} \\
\text { değeri* }^{*}\end{array}$} \\
\hline & Ort. \pm S.S. & $\begin{array}{l}\text { Median (Min / } \\
\text { Max) }\end{array}$ & Ort. \pm S.S. & $\begin{array}{l}\text { Median (Min / } \\
\text { Max) }\end{array}$ & \\
\hline Görüntülenme sayısı (n) & $\begin{array}{l}90259,00 \pm \\
82987,00\end{array}$ & $\begin{array}{l}59856,00 \\
(31305,00 / \\
339932,00)\end{array}$ & $\begin{array}{l}101663,00 \pm \\
179013,71\end{array}$ & $\begin{array}{l}57759,00 \\
(25010,00 / \\
692586,00)\end{array}$ & 0,256 \\
\hline Video süresi (dakika) & $1,81 \pm 2,20$ & $1,33(0,23 / 11,20)$ & $8,58 \pm 9,45$ & $4,27(1,08 / 31,00)$ & 0,003 \\
\hline $\begin{array}{l}\text { Yüklenme tarihinden beri } \\
\text { geçen zaman (gün) }\end{array}$ & $\begin{array}{l}2102,26 \pm \\
736,36\end{array}$ & $\begin{array}{l}2123,00(843,00 / \\
3403,00)\end{array}$ & $\begin{array}{l}1289,15 \pm \\
642,71\end{array}$ & $\begin{array}{l}1339,00(38,00 / \\
2732,00)\end{array}$ & 0,002 \\
\hline Beğenilme sayısı (n) & $\begin{array}{l}198,91 \pm \\
202,86\end{array}$ & $\begin{array}{l}94,00(3,00 / \\
706,00)\end{array}$ & $\begin{array}{l}529,92 \pm \\
979,19\end{array}$ & $\begin{array}{l}174,00(11,00 / \\
3600,00)\end{array}$ & 0,296 \\
\hline Beğenilmeme sayısı (n) & $\begin{array}{l}21,13 \pm \\
25,08\end{array}$ & $\begin{array}{l}15,00(1,00 / \\
93,00)\end{array}$ & $\begin{array}{l}44,38 \pm \\
72,84\end{array}$ & $\begin{array}{l}16,00(0,00 / \\
242,00)\end{array}$ & 0,609 \\
\hline Yorum Sayısı (n) & $\begin{array}{l}66,82 \pm \\
104,83\end{array}$ & $\begin{array}{l}14,00(0,00 / \\
318,00)\end{array}$ & $\begin{array}{l}70,08 \pm \\
130,42\end{array}$ & $\begin{array}{l}0,00(0,00 / \\
387,00)\end{array}$ & 0,292 \\
\hline Etkileşim İndeksi (\%) & $0,20 \pm 0,18$ & $0,12(-0,01 / 0,64)$ & $0,56 \pm 0,91$ & $0,26(0,04 / 3,45)$ & 0,044 \\
\hline İzlenme Oram (\%) & $\begin{array}{l}5364,41 \pm \\
6316,98\end{array}$ & $\begin{array}{l}3354,31(1042,11 / \\
24263,53)\end{array}$ & $\begin{array}{l}27618,18 \pm \\
70441,56\end{array}$ & $\begin{array}{l}4008,58(1195,06 / \\
256255,26)\end{array}$ & 0,365 \\
\hline
\end{tabular}
Tablo 2. Videoların bilgi sağlama kalitesine göre değerlendirilmesi.

Video sürelerinin orta/iyi kalitede olan videolarda $(8,58 \pm 9,45$ dakika) yetersiz kalitede olanlara $(1,81 \pm 2,20$ dakika) göre daha fazla olduğu $(p=0,003)$, benzer şekilde orta/iyi kalitedeki videoların $\% 0,56 \pm 0,91^{\prime}$ lik etkileşim indeksinin yetersiz kalitedeki videolardan $(\% 0,20 \pm 0,18)$ daha yüksek olduğu $(p=0,044)$ belirlenmiştir. Yüklenme tarihinden çalışmanın gerçekleştirildiği tarihe kadar geçen süre göz önünde bulundurulduğunda yetersiz kalitedeki videoların daha uzun zamandır YouTube ${ }^{T M^{\prime}}$ da yer aldığı görülmüştür $(p=0,002)$.

Video kaynağına göre 11 videonun bireysel, 9 videonun doktor ve 15 videonun ise ticari kaynaktan yüklendiği belirlenmiștir (Tablo 3). 
Tablo 3. Videoların yükleme kaynağına göre gruplar arası karşılaştırılması.

\begin{tabular}{|c|c|c|c|c|c|c|c|}
\hline & \multicolumn{2}{|c|}{$\begin{array}{l}\text { Bireysel Video Kaynakları } \\
(\mathrm{n}=11)\end{array}$} & \multicolumn{2}{|c|}{$\begin{array}{l}\text { Doktor Video Kaynaklart } \\
(\mathrm{n}=10)\end{array}$} & \multicolumn{2}{|c|}{$\begin{array}{l}\text { Ticari Video Kaynakları } \\
(\mathbf{n}=15)\end{array}$} & \multirow{2}{*}{$\begin{array}{l}\mathrm{P} \\
\text { degegeri* }\end{array}$} \\
\hline & Ort. \pm s.s. & $\begin{array}{l}\text { Median (Min / } \\
\text { Mnx) }\end{array}$ & ort. \pm S.s. & $\begin{array}{l}\text { Median (Min / } \\
\text { Max) }\end{array}$ & $\begin{array}{l}\text { Ort. } \pm \\
\text { s.s. }\end{array}$ & $\begin{array}{l}\text { Median (Min / } \\
\text { Max) }\end{array}$ & \\
\hline $\begin{array}{l}\text { Görüntülenme saysı } \\
\text { (n) }\end{array}$ & $\begin{array}{l}129194,00 \\
\pm \\
107009,79^{*}\end{array}$ & $\begin{array}{l}88688,00 \\
(31305,00 / \\
339932,00)\end{array}$ & $\begin{array}{l}120292,60 \pm \\
202466,55^{3}\end{array}$ & $\begin{array}{l}59340,00 \\
(25010,00 / \\
692586,00)\end{array}$ & $\begin{array}{l}51567,73 \\
\pm \\
20975,41^{\circ}\end{array}$ & $\begin{array}{l}49169,00 \\
(30906,00 / \\
110836,00)\end{array}$ & 0,042 \\
\hline Video sürresi (dakika) & $4,38 \pm 4,91$ & $\begin{array}{l}1,46(1,03 / \\
14,10)\end{array}$ & $1,85 \pm 1,23$ & $\begin{array}{l}1,44(1,08 / \\
5,28)\end{array}$ & $\begin{array}{l}5,76 \pm \\
9,31\end{array}$ & $\begin{array}{l}2.17(0.23 / \\
31,00)\end{array}$ & 0,946 \\
\hline $\begin{array}{l}\text { Yüklenme tarihinden } \\
\text { beri gecenn zaman } \\
\text { (güin) }\end{array}$ & $\begin{array}{l}1537,73 \pm \\
842,88\end{array}$ & $\begin{array}{l}1372,00(38,00 \\
/ 2855,00)\end{array}$ & $\begin{array}{l}1642,60 \pm \\
665,13\end{array}$ & $\begin{array}{l}1438,50 \\
(956,60 / \\
3096,00)\end{array}$ & $\begin{array}{l}2118,00 \pm \\
791,58\end{array}$ & $\begin{array}{l}2123,00 \\
(780,00 / \\
3403,00)\end{array}$ & 0,158 \\
\hline Beğenilme saysıs (n) & $\begin{array}{l}624,91 \pm \\
1030,47^{\circ}\end{array}$ & $\begin{array}{l}248,00(45,00 / \\
3600,00)\end{array}$ & $\begin{array}{l}316,10 \pm \\
310,50^{\mathrm{a}}\end{array}$ & $\begin{array}{l}206,00(11,00 / \\
1000,00)\end{array}$ & $\begin{array}{l}95,27 \pm \\
62,37^{\circ}\end{array}$ & $\begin{array}{l}83,00(3,00 / \\
201,00)\end{array}$ & 0,019 \\
\hline $\begin{array}{l}\text { Beğenilmeme saysıı } \\
\text { (n) }\end{array}$ & $\begin{array}{l}56,18 \pm \\
68,80^{\circ}\end{array}$ & $\begin{array}{l}41,00(7,00 / \\
242,00)\end{array}$ & $\begin{array}{l}25,80 \pm \\
48,36, \mathrm{wb}\end{array}$ & $\begin{array}{l}13,00(0,00 / \\
162,00)\end{array}$ & $\begin{array}{l}12,47 \pm \\
9,62^{\mathrm{b}}\end{array}$ & $\begin{array}{l}13,00(1,00 / \\
36,00)\end{array}$ & 0,048 \\
\hline Yorum saysı (n) & $\begin{array}{l}93,00 \pm \\
133,89\end{array}$ & $\begin{array}{l}23,00(0,00 / \\
314,00)\end{array}$ & $\begin{array}{l}83,10 \pm \\
127,66\end{array}$ & $\begin{array}{l}20,000(0,00 / \\
387,00)\end{array}$ & $\begin{array}{l}39,60 \pm \\
83,99\end{array}$ & $\begin{array}{l}12,00(0,00 / \\
318,00)\end{array}$ & 0.649 \\
\hline Etkilessim İ́ndeksi (\%) & $0,56 \pm 1,00$ & $\begin{array}{l}0,14(0,09 / \\
3,45)\end{array}$ & $0,33 \pm 0,20$ & $\begin{array}{l}0,32(0,04 / \\
0,64)\end{array}$ & $\begin{array}{l}0,17 \pm \\
0.13\end{array}$ & $\begin{array}{l}0,12(-0,01 / \\
0,49)\end{array}$ & 0,222 \\
\hline İzlenme Oranı (\%) & $\begin{array}{l}31750,55 \pm \\
7488,24^{\prime \prime}\end{array}$ & $\begin{array}{l}7027,85 \\
(1400,04 \\
256255,26)\end{array}$ & $\begin{array}{l}9190,24 \pm \\
17798,44^{2 . b}\end{array}$ & $\begin{array}{l}3692,68 \\
(1259,27 / \\
59654,26)\end{array}$ & $\begin{array}{l}2750,63 \pm \\
1257,15^{\circ}\end{array}$ & $\begin{array}{l}2885,87 \\
(1042,11 / \\
4959,11)\end{array}$ & 0,018 \\
\hline
\end{tabular}

Görüntülenme sayısının bireysel yükleme kaynaklarında ticari yükleme kaynaklarına göre istatistiksel olarak daha fazla olduğu ( $p=0,042)$, en fazla beğenilme ve beğenilmeme sayılarının sırasıyla bireysel, doktor ve ticari kaynaklar tarafından yüklenen videolarda görüldüğü tespit edilmiştir $(p<0,05)$. İzlenme oranı değerlendirildiğinde bireysel videoların ticari kaynaklı videolardan daha fazla izlenme oranına sahip olduğu görülmüştür ( $p=0,018)$.

Bireysel kaynaklı videoların \%81,8'inin, doktor kaynaklı videoların \%50'sinin, ticari kaynaklı videoların \%60'ının ve tüm videoların \%63,9'unun yetersiz olduğu görülmüştür. Ayrıca, ticari kaynaklı videoların \%73,3'ünün genel bilgi amaçlı yüklendiği, hasta kaynaklı videoların genel bilgi $(\% 36,4)$, hasta deneyimi $(\% 27,3)$ ve hasta bilgilendirme $(\% 36,4)$ amaçlı yükleme oranlarının benzer olduğu, doktor kaynaklı videoların ise \%70 oranında hasta bilgilendirme amaçlı olduğu belirlenmiştir. Çalışmaya dahil edilen tüm videoların \%50'si genel bilgi, \%41,7'si hasta bilgilendirme ve \%8,3'ü hasta deneyimini gösterme amacıyla yüklenmiştir (Tablo 4).

Tablo 4: Videoların bilgi sağlama kalitelerinin ve yüklenme amaçlarının video yükleme kaynakları ile ilişkisinin değerlendirilmesi.

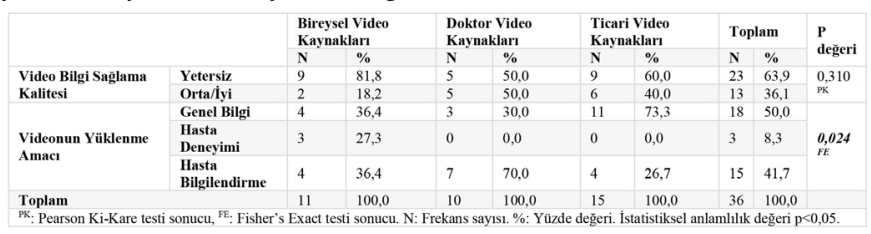

\section{TARTIŞMA}

Ortodontik tedavi gören hastaların tedaviler hakkında bilgi sahibi olması ve hekim ile uyumu tedavinin potansiyel başarısında önemli rol oynamaktadır ve ortodontik tedavileri araştıran hastaların birçoğu bilimsel platformlar yerine sosyal medyaya daha kolay bir şekilde erişebilmektedir.12 Son yıllarda internete ve sosyal medyaya olan ilginin artması göz önünde bulundurulduğunda ortodontik tedavi gören ve/veya ortodontik tedavi görmek isteyen bireylerin önemli bir kısmının YouTube ${ }^{\mathrm{TM}}$ video paylaşım platformu üzerinden tedavi alternatifleri, tedavi süreçleri ve tedavi sonuçları hakkında bilgi arayacağını düşünmenin gerçekçi bir yaklaşım olacağı düşünülmektedir.

Daha önceki çalışmalarda YouTube ${ }^{\mathrm{TM}}$, sabit ortodontik aygıtlar, hareketli ortodontik aygıtlar, üst çene genişletmesi, cerrahi yardımlı hızı üst çene genişlemesi, dudak-damak yarıkları, şeffaf plaklar, lingual ortodonti, gömülü dişler gibi çeşitli ortodonti konuları ile ilgili bir bilgi kaynağı olarak analiz edilmiştir., ${ }^{1,25-9,12-15}$ YouTube ${ }^{\mathrm{TM}}{ }^{\prime}$ daki ortodonti videolarının güvenilirliğini ve kalitesini değerlendiren önceki çalışmalarda değerlendirmeler yapıııken sadece Ingilizce dilinde bilgi veren videolar çalışmalara dahil edilmiştir. ${ }^{715}$ Çalışmamızda, diğer çalışmalardan farklı olarak Türkçe dilinde bilgi veren YouTube ${ }^{T M}$ videolarının bilgi içeriği, güvenilirliği ve kalitesi analiz edilmiştir.

Ortodonti ile ilgili YouTube ${ }^{\mathrm{TM}}$ video paylaşım platformunda arama terimleri seçilirken Google Trends uygulaması kullanılmış ve en çok aranan terim olarak "ortodonti" terimi anahtar kelime olarak seçilmiştir. Bilgi kaynağı olarak YouTube $^{\mathrm{TM}}{ }^{\prime}$ un analiz edildiği daha önceki çalışmalarda ${ }^{6,7}$, ${ }^{16}$ Google Trends uygulamasının kullanılması nedeniyle çalışmamızda da anahtar kelime seçiminde bu uygulama kullanıımıştır.

Çalışmamızda ortodonti ile ilgili YouTube platformunda yer alan Türkçe dilindeki videoların yüksek oranda (N:23, \%64,88) yetersiz puana (0-3 puan) sahip olduğu görülmüştür. Yakın zamanda ortodonti ile ilgili YouTube ${ }^{\mathrm{TM}}$ videolarını değerlendiren bir çalışmada videoların güvenilirliğinin düşük dereceli olduğu ve videoların genel kalitesinin ortalama olarak bulunduğu belirtilmiştir.7 Şeffaf plaklar ile ilgili YouTube ${ }^{\mathrm{TM}}$ videolarının değerlendirildiği başka bir çalışmada, zayıf içeriğe sahip videoların oranının \%67 olduğu gösterilmiş ve şeffaf plaklar konusunda genel olarak videolardan elde edilen bilgilerin güvenilirliğinin zayıf olduğu ve video içeriklerinin yetersiz olduğu

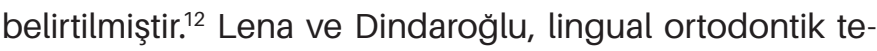
davileri içeren YouTube ${ }^{\mathrm{TM}}$ videolarının analizinde 32 videonun yüksek, 72 videonun ise düşük kalitede içeriğe sahip olduğunu göstermişler, sadece birkaç videoda lingual ortodontik tedavilerin biyomekaniklerinin veya prosedürlerinin tartışıldığını ve YouTube ${ }^{\mathrm{TM}}$ videolarının içeriğinin genellikle eksik olduğunu belirtmişlerdir. ${ }^{2}$ Benzer şekilde, hareketli ortodontik apareyler ile ilgili İngilizce dilindeki YouTube videolarının \%78,6'sının düşük içeriğe sahip olduğu ve apareylerin uygulanma zamanına, yararlarına ve kullanım önerilerine düşük içeriğe sahip videolarda daha az sıklıkla değinildiği rapor edilmiştir. ${ }^{6}$ Bununla birlikte çaıışmamızda orta/iyi kalitede bilgi içeriğine sahip videoların video süresinin ve etkileşim indeksinin düşük kalitede bilgi içeriğine sahip videolara göre daha yüksek olduğu, yüklenme tarihinden beri geçen gün sayısının ise daha düşük olduğu belirlenmiştir. Literatürde video süresi ve etkileşim indeksi ile video bilgi içeriği kalitesinin birbirleri ile pozitif bir korelasyon gösterdiği ve bilgi içeriği arttıkça video süresinin ve etkileşim indeksinin de artacağı bildirilmiştir. ${ }^{2,17}$ Çalışmamızın bulguları da bu literatür bilgisini destekleyecek şekildedir.

Çalışmamızda değerlendirilen videolar yükleme kaynağına göre üç grupta (bireysel, doktor, ticari) incelenmiştir. 
Ticari grupta yer alan videoların daha az görüntülenme sayısına sahip olması nedeniyle bu grupta yer alan videoların daha az beğenilme ve beğenilmeme sayısına sahip olduğunu düşünmekteyiz. Bununla birlikte, video grupları arasındaki bu farklıııların etkileşim indeksi üzerinde anlamlı bir farklılık oluşturmadığı görülmüştür. En yüksek izlenme oranının bireysel yükleme grubunda olmasının nedeni, bu gruptaki videoların görüntülenme sayısının en yüksek olması ve videoların yükleme tarihinden geçen zamanlar göz önünde bulundurulduğunda gruplar arasında farklılık olmaması, olarak belirtilebilir. Ortodonti ile ilgili en yüksek izlenme oranına sahip Türkçe dilindeki YouTube $^{\mathrm{TM}}$ videolarının bireysel yükleme grubunda yer alması ve bu grupta yer alan videoların çok yüksek oranda $(\% 81,8)$ yetersiz bilgi sağlama kalitesine sahip olması göz önünde bulundurularak hekimlerin hastalarını doğru bilgi kaynaklarına yönlendirmeleri tavsiye edilebilir. Doktor kaynaklı videoların $\% 50$ oranında orta/iyi kalitede olması ve bu videolarda hasta bilgilendirme oranının \%70 olması Türkçe dilinde ortodonti ile ilgili bilgi veren videolardan elde edilecek bilgilerin doktor kaynaklı videolardan elde edilmesinin daha uygun bir yaklaşım olacağını düşündürmüştür.

YouTube $^{\mathrm{TM}}$ video paylaşım platformunda yer alan videolar birçok dilde içeriğe sahip olabilmektedir. Çalışmamız sadece Türkçe dilinde yüklenen videoların analizini içerecek şekilde sınırlandırılarak ülkemizde yaşayan veya Türkçe dilinde doğru bilgiye ulaşmayı düşünen bireylerin YouTube $^{\top M}$ üzerinden ulaşabileceği bilgilerin kalitesi değerlendirilmiştir. YouTube ${ }^{\mathrm{TM}}$ video içeriklerinin video izlenme, beğenilme ve beğenilmeme sayılarının ve izlenme oranlarının sürekli olarak değişebileceği ve videolar ile ilgili standardizasyon eksikliği göz önünde bulundurulmalıdır. Bunlar çalışmamız için bir sınırlama olarak görülebilir ancak çalışmanın gerçekliğini sağlamak ve abartıı veya önyargılı içerik olasııı̆ını azaltmak için reklam, ders ve ilgisiz nitelikteki videolar dahil edilmemiştir. Bu sınırlamalara rağmen, bu yöntem, nispeten öznel doğası ne olursa olsun güvenilir kabul edilebilecek ön bilgi elde etmek için hala kullanılabilir olduğu düşünülmektedir. Yapılacak ileri çalışmalarda belirli zaman aralığındaki değişim değerlendirilerek videoları geçerliliği incelenebilir. Çalışmamızda ortodonti ile ilgili YouTube videolarının bilgi içeriğinin yüksek oranda yetersiz olduğu bu nedenle profesyonel sağlık hizmeti sunan hekimlerin ve kurumların bu platformda yer alan bilgilerin güvenilirliği hakkında ortodontik tedavi gören ve/veya ortodontik tedavi görmek isteyen bireyleri doğru şekilde yönlendirmelerinin gerekli olduğu düşünülmüștür.

\section{SONUÇ}

Ortodonti ile ilgili YouTube ${ }^{\mathrm{TM}}$ video paylaşım platformunda yer alan Türkçe videolar genel olarak yetersiz bilgi kalitesine sahiptir. Doktor yükleme kaynaklarında yer alan bilgilerin yaklaşık olarak yarısının yetersiz bilgi kalitesine sahip olması göz önünde bulundurulmalı ve ortodontik tedaviler ile ilgili bilgi sağlayan video içeriklerinin hekimler tarafından kalitesinin sorgulanması sağlanmalıdır. Ortodontistler, diş hekimleri ve ağız-diş sağlığı hizmeti sunan kuruluşlar internet üzerinden bilgi sağlayan YouTube ${ }^{\mathrm{TM}}$ gibi platformlarda yer alan bilgilerin yetersizliğini bilerek hastaların güvenilir bilgi kaynaklarına yönlendirilmesini sağlamalıdır.

\section{KAYNAKLAR}

1.Al-Silwadi FM, Gill DS, Petrie A, Cunningham SJ. Effect of social media in improving knowledge among patients having fixed appliance orthodontic treatment: a single-center randomized controlled trial. Am J Orthod Dentofacial Orthop 2015; 148: 231-237.

2.Lena Y, Dindaroğlu F. Lingual orthodontic treatment: A YouTube $^{\text {tm }}$ video analysis. Angle Orthod 2018; 88: 208214.

3.Meade MJ, Sooriakumaran P, Dreyer CW. Orthodontic retention and retainers: Quality of information provided by dental professionals on YouTube. Am J Orthod Dentofacial Orthop 2020; 158: 229-236.

4. Hassona Y, Taimeh D, Marahleh A, Scully C. YouTube as a source of information on mouth (oral) cancer. Oral Dis 2016; 22: 202-208.

5.Korkmaz YN, Buyuk SK. YouTube as a Patient-Information Source for Cleft Lip and Palate. Cleft Palate Craniofac J 2020; 57: 327-332.

6.Merve Nur Aydın HY. Hareketli ortodontik apareyler ile ilgili youtube ${ }^{\mathrm{Tm}}$ videolarının içerik analizi. Yeditepe J Dent 2020; 16:220-225.

7.Kılınç DD, Sayar G. Assessment of reliability of youtube videos on orthodontics. Turk J Orthod 2019; 32: 145-150. 8. Atilla AO, Öztürk T. Maksiller Ekspansiyon İçin Bilgi Kaynağı Olarak Youtube'un Video Analizi ile Değerlendirilmesi. Selcuk Dent J 2020; 7 :494-499.

9.Hatipoğlu Ş, Gaş S. Is Information for Surgically Assisted Rapid Palatal Expansion Available on YouTube Reliable? J Oral Maxillofac Surg 2020; 78: 1017.e1-1017.e10.

10. Hegarty E, Campbell C, Grammatopoulos E, DiBiase AT, Sherriff $M$, et al. YouTube ${ }^{\text {Tw }}$ as an information resource for orthognathic surgery. J Orthod 2017; 44: 90-96.

11.Desai $T$, Shariff $A$, Dhingra $V$, Minhas $D$, Eure $M$, et al. Is content really king? An objective analysis of the public's response to medical videos on YouTube. PLoS One 2013;8:e82469.

12.Ustdal G, Guney AU. YouTube as a source of information about orthodontic clear aligners. Angle Orthod 2020; 90: 419-424.

13.Bozkurt AP, Gaş S, Zincir ÖÖ. YouTube video analysis as a source of information for patients on impacted canine. Int Orthod 2019; 17: 769-775.

14.Pasaoglu Bozkurt A, Aras I. Cleft Lip and Palate YouTu- 
be Videos: Content Usefulness and Sentiment Analysis. Cleft Palate Craniofac J 2020;1055665620948722.

15.Guo J, Yan X, Li S, Van der Walt J, Guan G, et al. Quantitative and qualitative analyses of orthodontic-related videos on YouTube. Angle Orthod 2020; 90: 411-418.

16.Yavuz MC, Buyuk SK, Genc E. Does YouTube ${ }^{\text {mm }}$ offer high quality information? Evaluation of accelerated orthodontics videos. Ir J Med Sci 2020; 189: 505-509.

17. Coban G, Buyuk SK. YouTube as a Source of Information for Craniofacial Distraction Osteogenesis. J Craniofac Surg 2021. 